\title{
FUTUROS AGROPECUÁRIOS EM PORTFÓLIOS DE MÁXIMA UTILIDADE ESPERADA $^{1}$
}

\author{
Rodrigo Lanna Franco da Silveira ${ }^{2}$ \\ Geraldo Sant'Ana de Camargo Barros ${ }^{3}$
}

\begin{abstract}
Resumo: Este estudo analisou a composição de portfólios de máxima utilidade esperada, considerando ações, títulos de renda fixa, ouro, dólar e contratos futuros agropecuários, negociados na Bolsa de Valores, Mercadorias e Futuros (BM\&FBOVESPA), no período de 1994 a 2007. A partir das combinações ótimas de risco-retorno, seguindo o algoritmo de Markowitz, e do uso de uma função utilidade quadrática, com adoção de diferentes graus de aversão ao risco, foram obtidas as carteiras de máxima utilidade esperada. No período completo, os derivativos agropecuários não estiveram presentes nesses portfólios. Porém, com a divisão da amostra em dois e três períodos, tais papeis foram incluídos nos intervalos de tempo pertencentes à década de 2000. Além disso, em geral, com o aumento da aversão ao risco, a participação desses títulos na carteira teve queda.
\end{abstract}

Palavras-chave: Portfólio, contratos futuros agropecuários, utilidade.

\section{Introdução}

Os contratos futuros representam um tipo de derivativo transacionado, exclusivamente, em bolsas de mercadorias, em que são estabelecidos acordos de compra e venda de um ativo, para certa data futura, a um preço predeterminado. A negociação de tais papeis permite, por um lado, que as partes envolvidas se protejam contra oscilações não desejadas nos preços de commodities ou de ativos financeiros subjacentes aos contratos, mediante operações de hedge, e, por outro, que agentes especuladores negociem tais papeis, com o objetivo de obterem ganhos

Recebido em: 12/06/2009; Aceito em:11/09/2009.

2 Professor no Instituto de Economia da Universidade de Campinas - UNICAMP, Campinas, SP. E-mail: rodrigolanna@eco.unicamp.br.

3 Professor Titular no Departamento de Economia, Administração e Sociologia da ESALQ/ USP, Piracicaba, SP. E-mail: gscbarro@esalq.usp.br. 
com as oscilações dos preços futuros, utilizando-os como títulos de renda variável.

Verifica-se que, a partir da década de 90, a transação de derivativos com vistas em investimento tem tido expansão no mercado financeiro mundial. Conforme o Center for International Securities and Derivatives Markets (2006), entre 1995 e 2005, nos Estados Unidos, os ativos administrados por Commodity Trader Advisor (CTA) e por Commodity Pool Operator (CPO), nos chamados managed futures, cresceram de US\$ 22 bilhões para US\$ 132 bilhões ${ }^{4}$. Segundo esta mesma fonte, investidores institucionais e bancos de investimento têm incluído os managed futures em seus portfólios, tendência que também pode ser constatada no Brasil. Conforme Quaranta (2007), os fundos de pensão brasileiros vêm utilizando, de forma crescente, os mercados futuros, mesmo que de forma ainda tímida, com fins de hedge e de investimento. Fundos multimercados alavancados têm feito uso de tais papeis em busca de maiores rentabilidades, assumindo riscos mais elevados.

Nesse contexto incluem-se os contratos futuros agropecuários. A alocação desses derivativos em carteiras de investimento tem sido analisada desde o final da década de 70 e início da de 80 , com os trabalhos seminais de Greer (1978) e Bodie e Rosansky (1980). O interesse fundamental nesses títulos baseia-se na baixa correlação de seus retornos com as rentabilidades das ações e títulos de renda fixa, o que permite uma possível diversificação de risco e aumento na performance do portfólio.

As pesquisas sobre o tema avançaram nas décadas posteriores, sendo as mais recentes, para os mercados norte-americanos, as de Jensen et al. (2000), Jensen et al. (2002), Edwards e Caglayan (2001), Egelkraut et al. (2005), Akey (2005), Erb e Harvey (2006), Gorton e Rouwenhorst (2006), Idzorek (2006), You e Daigler (2007) e Szado (2009). No Brasil, podem-se apontar Mattos e Ferreira Filho (2003), Costa e Piacenti (2008) e Silveira e Barros (2009).

\footnotetext{
4 Os managed futures consistem em um tipo de fundo de investimento cuja carteira é formada por contratos de derivativos financeiros (títulos, moedas e índices de ações) e de commodities (grãos, metais, animais, alimentos e combustíveis). A negociação de tais papeis é feita por CTA e, ou, CPO, em que se utiliza, em geral, análise técnica para a decisão de compra ou de venda.
} 
Tais trabalhos utilizaram, em geral, o Modelo de Média e Variância, exceto You e Daigler (2007) e Costa e Piacentini (2008), que fizeram uso da metodologia de Value at Risk. Verificou-se, em grande parte das análises, a existência de ganhos de performance com a inclusão de futuros sobre commodities em carteiras de ações e títulos. Porém, em um contexto isolado, o investimento nesses derivativos não foi, em boa parte dos artigos, uma estratégia viável, já que representou alto risco para o retorno médio observado.

No entanto, verifica-se que os impactos na utilidade esperada do investidor, quando da inclusão de contratos futuros sobre commodities em uma carteira, não foram levados em conta. Anson (1999) inseriu tal aspecto, partindo de um portfólio composto por ações e títulos negociados nos Estados Unidos. Assim, em vez de analisar os portfólios ótimos com o Modelo de Média e Variância, esse autor avaliou como a política de investimentos é guiada, quando se considera a maximização da utilidade esperada do investidor. Ao se utilizar uma função utilidade quadrática, os resultados indicaram que, à medida que se elevava a aversão ao risco, havia aumento na participação dos contratos futuros no portfólio. A explicação para tal fato consistiu no potencial que esses derivativos possuíam para diversificar o risco da carteira.

Nesse contexto, o presente estudo objetivou analisar a composição das carteiras de máxima utilidade esperada, no período de 1994 a 2007, considerando ações, títulos de renda fixa, ouro, dólar e futuros agropecuários, sendo estes últimos negociados na Bolsa de Valores, Mercadorias e Futuros (BM\&FBOVESPA). Assim, busca-se avaliar, adotando diferentes graus de aversão ao risco do investidor, qual a participação desses derivativos nos portfólios ótimos. 


\section{Metodologia}

Com vistas em atingir os objetivos expostos, adota-se a metodologia aplicada em Anson (1999). O comportamento do investidor segue uma função de utilidade quadrática, como apresentada na equação (1).

$$
E\left(U_{i}\right)=\mu_{p}^{*}-\sigma_{p}^{2^{*}} b_{i}
$$

em que $E\left(U_{i}\right)$ é a utilidade esperada do investidor; $\mu_{p}{ }_{p}$, retorno esperado ótimo da carteira; $\sigma_{p}^{2}{ }^{*}$, variância ótima dos retornos do portfólio; e $b_{i}$, medida de aversão ao risco. Seguindo o trabalho de Anson (1999) e de Fabozzi et al. (2006), definem-se cinco valores para $b_{i}: 0,0 ; 0,5 ; 1,0 ; 2,0$ e 4,0. Quanto maior $b_{i}$, mais avesso ao risco será o agente.

As combinações ótimas de risco-retorno são obtidas pelo algoritmo de Markowitz (1952, 1956 e 1959) - Modelo de Média e Variância, no qual, para certo nível de risco do portfólio, $\sigma_{\mathrm{p}}=\sigma_{0}$, maximiza-se o retorno médio (FABOZZI et al., 2006) - equação (2).

$$
\begin{aligned}
& \max _{x} \quad x^{\prime} \mu \\
& \text { Sujeito a: } \sigma_{0}=\sqrt{x^{\prime} \Omega x} ; \sum_{i=1}^{n} X_{i}=1 ; 0 \leq X_{i} \leq 1 \quad \text { em que, } i=1, \ldots, n .
\end{aligned}
$$

em que $x$ ' $\mu$ representa o retorno médio da carteira, $\mu_{p} ; x$ ' é um vetor de ordem $(1 \times n)$, em que estão presentes os pesos de cada ativo individual; e $X$ pertence ao portfólio $(i=1,2, \ldots, n)$. A soma de tais pesos deve ser igual a um, não sendo permitido, neste trabalho, que qualquer ativo possua peso inferior a zero e, ou, superior a um (inexistência de vendas a descoberto). Já $\mu$ consiste em um vetor $(n \times 1)$ de retornos esperados dos ativos individuais, $\mu i$, obtidos mediante o cálculo de médias aritméticas das rentabilidades do papel em questão; $\sigma_{p}$ é o risco da carteira, representado pelo desvio-padrão de seus retornos, sendo $\Omega$ igual à matriz, de ordem $(n \times n)$, de covariância das rentabilidades dos $n$ papeis, sendo 
tal medida calculada dois a dois - títulos $i$ e $j\left(\sigma_{i j}\right)$. Sendo $i=j$, tem-se o risco individual de cada ativo.

Cabe observar que na análise individual do ativo utiliza-se a razão de Sharpe $(R S)$ - equação (3). Quanto maior $R S$, melhor o desempenho do ativo.

$$
R S=\frac{\mu_{i}-R_{f}}{\sigma_{i}}
$$

em que $R_{f}$ é a taxa de juros livre de risco, representada pela taxa Selic.

As combinações ótimas de risco-retorno são obtidas tanto para a carteira inicial (composta por ações, títulos, ouro e dólar), como também para os portfólios formados pelos ativos citados mais os futuros agropecuários, no período de 1994 a 2007. O ativo somente será considerado na análise se apresentar série de retorno, em todo período em estudo. Assim, com vistas em contemplar os derivativos que não tiveram negociações nos anos iniciais, em outros estudos também se divide a amostra em dois (1994 a 2000 e 2001 a 2007) e três períodos (1994 a 1998, 1999 a 2003 e 2004 a 2007).

Duas questões precisam ser observadas sobre o método a ser usado. Em primeiro lugar, no Modelo de Média e Variância, pressupõe-se que os preços dos ativos tenham distribuição normal ou, alternativamente, que os agentes, em suas funções utilidade, concentrem-se apenas na média e na variância da distribuição. Em segundo lugar, a utilização de uma função utilidade quadrática justifica-se pelo fato de suas variáveis de interesse serem exclusivamente os dois primeiros momentos da distribuição dos retornos da carteira, como é demonstrado a seguir (ELTON et al., 2004; FABOZZI et al., 2006).

A partir de um horizonte temporal de um período, o problema de maximização da utilidade esperada, $E\left[U\left(W_{1}\right)\right]$, é representado pela equação (4). 
$\max _{w} E\left[U\left(W_{1}\right)\right]=E\left\{U\left[W_{0}\left(1+x^{\prime} \mu\right)\right]\right\}$

Sujeito a $: \sum_{i=1}^{n} X_{i}=1$.

em que $W_{0}$ e $W_{1}$ são iguais à riqueza inicial e após um período do investidor, respectivamente.

Admitindo uma função utilidade quadrática, do tipo

$U(W)=W-b W^{2}$,

chega-se a

$$
\begin{aligned}
E\left[U\left(W_{1}\right)\right] & =E\left(W_{1}-b W_{1}^{2}\right) \\
& =E\left(W_{1}\right)-b E\left(W_{1}^{2}\right) \\
& =E\left(W_{1}\right)-b\left\{\sigma_{w}^{2}+\left[E\left(W_{1}\right)\right]^{2}\right\}
\end{aligned}
$$

em que $\sigma_{w}^{2}=E\left(W_{1}^{2}\right)-\left[E\left(W_{1}\right)\right]^{2}$.

Assim, verifica-se que a utilidade esperada do agente somente depende dos dois primeiros momentos da distribuição de probabilidade de $W$.

Vale observar, no entanto, que tal abordagem possui limitações. Em relação à hipótese da distribuição normal, verifica-se que grande parte dos ativos financeiros não se distribui normalmente. Quanto ao uso função quadrática, nota-se que, além da hipótese de a ausência de saciedade (preferência por mais riqueza a menos riqueza) ser obedecida apenas em determinado intervalo de valores de $W$, a função apresenta aversão absoluta e aversão relativa crescentes a risco - ou seja, à medida que o agente aumenta $W$, o montante aplicado em ativos de risco e a participação desta aplicação 
têm queda ${ }^{5}$. Adicionalmente, ao considerar o desvio-padrão como medida de risco, postula-se que o investidor seja avesso, na mesma magnitude, a desvios que ocorrem abaixo e acima da média.

Entretanto, na defesa do uso de tais hipóteses há vários argumentos. Damodaran (2009: p. 88 e 89) mencionou que os defensores de tal abordagem

“... justificam uso da distribuição normal ao afirmarem que os retornos podem obedecer à distribuição lognormal (em cujo caso o logaritmo dos retornos deve obedecer à distribuição normal). Eles também argumentam que os retornos sobre as carteiras (e não sobre ações individuais) são mais simétricos e, portanto, estão mais próximos da normalidade, sobretudo em períodos curtos de tempo".

Além disso, esse autor enfatizou que a parcimônia é fator principal para a adoção de tal abordagem. Neste aspecto, Fabozzi et al. (2006) citaram alguns estudos (Pulley, 1981; Kroll et al., 1984; Cremers et al., 2003), os quais demonstraram que os ganhos ao adotar modelos mais complexos e próximos da realidade, em relação ao Modelo da Média e Variância, são bastante pequenos.

\subsection{Posições com futuros agropecuários}

Este trabalho considerou seis posições em futuros agropecuários da BM\&FBOVESPA. Quatro delas consistem em estratégias estáticas, baseadas na compra ou na venda de contratos de primeiro vencimento ou de prazo mínimo de seis meses até a expiração ${ }^{6}$, em que é mantida a mesma posição até o último dia de negociação ${ }^{7}$.

\footnotetext{
Outros tipos de função utilidade podem ser considerados, tais como logarítmica, exponencial, potência, linear, entre outras. As funções logarítmicas, por exemplo, atendem às condições de não saciedade, aversão ao risco, aversão absoluta decrescente e aversão relativa constante. Uma análise de cada uma delas foi feita por Elton et al. (2004), Fabozzi et al. (2006) e Damodaran (2009).

6 No caso de inexistência de liquidez para este prazo, utiliza-se o derivativo de maior prazo até o vencimento. 7 Os contratos sem cláusula de liquidação financeira no vencimento possuem cotações consideradas até o dia anterior ao início do período de emissão do aviso de entrega. Além disso, cabe mencionar que derivativos com cotações em dólares tiveram seus preços convertidos pela PTAX média de compra e venda do dia.
} 
As duas outras posições são dinâmicas, obtidas a partir de médias móveis de 21 e de 126 dias úteis sobre os preços futuros de primeiro vencimento, dado que são indicadores bastante utilizados pelos agentes de mercado, para mostrar tendência de curto prazo (21 dias úteis) e de longo prazo (126 dias úteis). Desenvolve-se uma regra de negócios em que os contratos serão comprados (vendidos), se o preço de ajuste estiver acima (abaixo) da média móvel em questão, pois tal situação indicará tendência de alta (baixa). $\mathrm{O}$ uso de tal instrumento se deve à possibilidade de criar uma regra de negociação sem critérios subjetivos.

Cabe, ainda, salientar que o trabalho tem as seguintes hipóteses: a) Custos com corretagem e impostos iguais a zero; b) Inexistência de alavancagem - ao transacionar contratos, os agentes depositam colaterais no valor de $100 \%$ do derivativo, como feito em Bodie e Rosansky (1980), Fortenbery e Hauser (1990) e Gorton e Rouwenhorst (2006); c) As margens de garantias não possuem rendimentos - com isso, a rentabilidade do derivativo é baseada somente na variação do preço futuro da commodity; d) Nas posições dinâmicas, o agente somente altera sua posição (para comprado quando estava anteriormente vendido ou vice-versa) no primeiro dia útil do mês, a partir da sinalização da regra verificada no dia anterior - não se permite, portanto, mudança de posição em um mesmo mês, com vistas em amenizar os possíveis impactos que a hipótese de inexistência de custos de corretagem teria sobre os resultados.

\subsection{Dados do estudo}

Os dados utilizados no estudo consistem nos preços dos ativos componentes da carteira de investimento em análise, que são: a) Ações representadas pelo Índice da Bolsa de Valores de São Paulo IBOVESPA; b) Títulos de renda fixa, em que são utilizadas as taxas ANBID $^{8}$ e SELIC; c) Ouro, cujos preços à vista são obtidos na BM\&FBOVESPA; d) Dólar, que representa os investimentos atrelados

Taxa calculada pela Associação Nacional dos Bancos de Investimento, formada pela média das rentabilidades prefixadas, ponderadas pelos montantes captados, dos Certificados de Depósito Bancário - CDB, Certificados de Depósito Interfinanceiro - CDI e dos Recibos de Depósito Bancário - RDB. 
à taxa de câmbio R $\$ / U S \$$, divulgada e calculada pelo Banco Central do Brasil; e) Contratos futuros agropecuários (de açúcar, álcool anidro, boi gordo, café arábica, milho e soja), negociados na BM\&FBOVESPA. A amostra abrange o período de agosto de 1994 a dezembro de 2007 - 161 observações. Dentre os papéis atrelados às commodities, apenas os futuros de café arábica e boi possuem contratos negociados em todo o período considerado?

\section{Resultados e discussão}

No período de agosto de 1994 e dezembro de 2007, os futuros agropecuários apresentaram baixo desempenho (em razão do pequeno retorno médio e alto risco) e correlações em relação aos títulos/ações, em geral, próximas a zero ${ }^{10}$ - Tabela 1 . Tais constatações foram condizentes com os resultados obtidos, em grande parte, nos artigos citados na introdução deste trabalho. Vale observar que somente os futuros de café e boi gordo foram considerados, pois constituíram os únicos derivativos que apresentaram negociação para o período completo. Ao analisar, especificamente, esses derivativos, nota-se que, para o café, a posição dinâmica com média móvel de 126 dias úteis teve o maior retorno ( $1,02 \%$ a.m.), enquanto para o boi gordo as posições compradas de primeiro vencimento foram as mais rentáveis $(0,46 \%$ a.m. $)$. Além disso, a volatilidade dos retornos, no mercado futuro de café, foi sempre $100 \%$ superior aos resultados obtidos para os derivativos de boi gordo, levando em conta as mesmas estratégias.

\footnotetext{
9 O número de observações e o mês inicial da amostra para os futuros agropecuários foram: a) Açúcar - 147 observações, com dados a partir de outubro de 1995; b) Álcool - 81, abril de 2000; c) Milho - 134, novembro de 1996; d) Soja - 130, outubro de 1995; café e boi gordo - 161, agosto de 1994. Vale observar que os futuros de álcool foram substituídos pelos derivativos de etanol, após junho de 2007. Além disso, os futuros de soja não apresentaram transações entre maio de 2001 e setembro de 2002. Adicionalmente, cabe notar que os futuros de algodão, bezerro e café robusta não foram incluídos no estudo, devido à baixa liquidez de seus mercados.

${ }^{10}$ Como a cotação dos contratos futuros de café arábica é em dólar, sendo o mesmo verificado para o derivativo de boi gordo, entre 1994 e 2000, verificou-se alta correlação entre os retornos do dólar e desses papeis. Altos coeficientes também foram obtidos entre as rentabilidades do ouro e dos futuros em questão, pois as cotações deste metal e da taxa de câmbio seguiram a mesma tendência.
} 
Tabela 1 - Retorno médio, risco e correlações entre as rentabilidades dos ativos, entre agosto de 1994 e dezembro de 2007

\begin{tabular}{|c|c|c|c|c|c|c|c|c|c|c|c|c|}
\hline \multirow{2}{*}{ Ativo } & \multirow{2}{*}{$\begin{array}{l}\text { Retorno } \\
\text { médio }\end{array}$} & \multirow{2}{*}{$\begin{array}{l}\text { Risco } \\
\text { (\% a.m) }\end{array}$} & \multirow{2}{*}{$\begin{array}{l}\text { Razão de } \\
\text { Sharpe } \\
\text { (\%a.m.) }\end{array}$} & \multicolumn{9}{|c|}{ Correlações } \\
\hline & & & & Ouro & & IBOV & & Dólar & & SELIC & & ANBID \\
\hline Ouro & 1,15 & 7,76 & $-0,08$ & 1 & & & & & & & & \\
\hline IBOVESPA & 2,20 & 9,85 & 0,04 & $-0,02$ & & 1 & & & & & & \\
\hline Dólar & 0,60 & 6,85 & $-0,17$ & 0,84 & $* * *$ & $-0,18$ & $* *$ & 1 & & & & \\
\hline SELIC & 1,79 & 0,81 & 0,00 & $-0,04$ & & 0,08 & & 0,01 & & 1 & & \\
\hline Taxa ANBID & 1,75 & 0,77 & $-0,05$ & $-0,05$ & & 0,09 & & 0,01 & & 0,97 & $* * 8$ & 1 \\
\hline Futuro de boi - CC & 0,46 & 5,47 & $-0,24$ & 0,25 & $* * *$ & $-0,01$ & & 0,26 & $* * *$ & 0,03 & & 0,04 \\
\hline Futuro de café - CC & $-0,16$ & 11,94 & $-0,16$ & 0,27 & $* * 3$ & 0,07 & & 0,36 & $* * *$ & $-0,03$ & & $-0,03$ \\
\hline Futuro de boi - CL & 0,34 & 5,05 & $-0,29$ & 0,38 & $* * 3$ & $-0,04$ & & 0,43 & $* * *$ & 0,02 & & 0,04 \\
\hline Futuro de café - CL & 0,23 & 11,93 & $-0,13$ & 0,28 & $* * *$ & 0,08 & & 0,37 & $* * *$ & $-0,03$ & & $-0,03$ \\
\hline Futuro de boi - DIN 1 & $-0,10$ & 5,48 & $-0,34$ & 0,22 & $* * *$ & $-0,01$ & & 0,26 & $* * *$ & $-0,25$ & $* * *$ & $-0,22$ \\
\hline Futuro de café - DIN 1 & 0,45 & 11,96 & $-0,11$ & 0,20 & $* * *$ & 0,02 & & 0,21 & $* * *$ & 0,00 & & 0,00 \\
\hline Futuro de boi - DIN 2 & $-0,62$ & 4,59 & $-0,53$ & 0,28 & $* * *$ & $-0,11$ & & 0,28 & $* * *$ & $-0,07$ & & $-0,05$ \\
\hline Futuro de café - DIN 2 & 1,02 & 12,00 & $-0,06$ & 0,28 & $* * 8$ & 0,01 & & 0,28 & $* * *$ & $-0,07$ & & $-0,09$ \\
\hline
\end{tabular}

Fonte: Resultados da pesquisa.

Notas: *** Significativo a $1 \%$; ** significativo a $5 \%$.

$\mathrm{VL}=$ posição vendida longa; $\mathrm{VC}=$ posição vendida curta; $\mathrm{CL}=$ posição comprada longa; $\mathrm{CC}=$ posição comprada curta; DIN 1 = posição dinâmica com média móvel de 21 dias úteis; DIN 2 = posição dinâmica com média móvel de 126 dias úteis.

A partir das combinações ótimas dos portfólios com e sem derivativos agropecuários e dos cinco valores do coeficiente de aversão ao risco do investidor $\left(b_{i}\right)$, obtiveram-se as carteiras que levaram à utilidade máxima. Tais portfólios foram compostos pelo IBOVESPA e, ou, títulos atrelados à SELIC. Para os agentes neutros ao risco, $b_{i}=0$, a maior utilidade foi atingida pela carteira formada integralmente pelo IBOVESPA. Com o aumento da aversão ao risco, as ações foram gradativamente substituídas pelos papeis indexados à SELIC - Tabela 2. Não houve, portanto, participação dos futuros agropecuários nas carteiras de máxima utilidade, já que se notou fraco desempenho desses derivativos (perceptível pelas baixas razões de Sharpe), o qual anulou o potencial desses papeis na diversificação do risco da carteira. 
Tabela 2 - Retorno médio, risco e composição das carteiras que maximizavam a utilidade do investidor, no período de 1994 a 2007

\begin{tabular}{|c|c|c|c|c|c|c|c|c|c|}
\hline \multirow{2}{*}{$A_{i}$} & \multirow{2}{*}{$\begin{array}{l}\text { Retorno } \\
\text { médio } \\
\text { (\%a.m) }\end{array}$} & \multirow{2}{*}{$\begin{array}{c}\text { Risco } \\
(\% \text { a.m) }\end{array}$} & \multicolumn{7}{|c|}{ Pesos na carteira $(\%)$} \\
\hline & & & Ouro & IBOVESPA & Dólar & SELIC & ANBID & Boi & Café \\
\hline $\mathrm{L}=0,0$ & 2,20 & 9,85 & - & 100,00 & - & - & - & - & - \\
\hline $\mathrm{L}=0,5$ & 1,95 & 3,96 & - & 39,51 & - & 60,49 & - & - & - \\
\hline $\mathrm{L}=1,0$ & 1,88 & 2,37 & - & 22,71 & - & 77,29 & - & - & - \\
\hline $\mathrm{L}=2,0$ & 1,86 & 1,93 & - & 17,91 & - & 82,09 & - & - & - \\
\hline $\mathrm{L}=4,0$ & 1,81 & 0,99 & - & 5,91 & - & 94,09 & - & - & - \\
\hline
\end{tabular}

Fonte: Resultados da pesquisa.

Ao dividir a amostra em dois períodos, as mesmas constatações feitas valeram para os anos de 1994 a 2000,quais sejam, baixo desempenho individual e correlações estatisticamente iguais a zero entre os retornos dos futuros agropecuários e as ações/títulos. Novamente, somente os contratos de café arábica e boi gordo representaram os derivativos agropecuários.

Já no intervalo de tempo 2001 e 2007, em que foram incluídas posições em futuros de milho, açúcar e álcool às já existentes de café e boi gordo, observou-se melhora no desempenho individual dos futuros agropecuários, quando analisadas posições dinâmicas com médias móveis de 21 dias úteis. A estratégia dinâmica em futuro de milho, DIN1, teve retorno médio relativamente elevado, 2,26\% a.m, para um risco de 9,16\% a.m, resultando na maior razão de Sharpe, dentre os ativos considerados. Bons resultados também foram constatados nas estratégias DIN1 de açúcar e álcool, como se verifica na Tabela 3. Vale ressaltar que somente foram apresentados nesta tabela os dados das posições curtas e dinâmicas de 21 dias úteis em derivativos, pois foram as que obtiveram os melhores desempenhos. 
Tabela 3 - Retorno médio, risco e correlações entre as rentabilidades dos ativos, de janeiro de 2001 a dezembro de 2007

\begin{tabular}{|c|c|c|c|c|c|c|c|c|c|c|c|}
\hline \multirow{2}{*}{ Ativo } & \multirow{2}{*}{$\begin{array}{l}\text { Retorno } \\
\text { médio } \\
\text { (\% a.m) }\end{array}$} & \multirow{2}{*}{$\begin{array}{l}\text { Risco } \\
(\% \text { a.m) }\end{array}$} & \multirow{2}{*}{$\begin{array}{c}\text { Razão de } \\
\text { Sharpe (\% } \\
\text { a.m) }\end{array}$} & \multicolumn{8}{|c|}{ Correlações } \\
\hline & & & & Ouro & & IBOV & & Dólar & & SELIC & ANBID \\
\hline Ouro & 1,40 & 6,40 & 0,01 & 1,00 & & & & & & & \\
\hline IBOVESPA & 2,01 & 7,62 & 0,09 & $-0,30$ & ${ }^{* * *}$ & 1,00 & & & & & \\
\hline Dólar & 0,05 & 5,87 & $-0,22$ & 0,73 & ${ }^{* * *}$ & $-0,62$ & $*$ & 1,00 & & & \\
\hline SELIC & 1,35 & 0,28 & 0,00 & 0,00 & & 0,05 & & 0,01 & & 1,00 & \\
\hline Taxa ANBID & 1,34 & 0,27 & $-0,04$ & $-0,04$ & & 0,05 & & $-0,05$ & & 0,94 & 1,00 \\
\hline Futuro de boi - CC & $-0,03$ & 3,57 & $-0,39$ & 0,11 & & $-0,06$ & & 0,07 & & $-0,17$ & $-0,14$ \\
\hline Futuro de café - CC & $-0,38$ & 8,98 & $-0,19$ & 0,28 & ${ }^{* * *}$ & $-0,11$ & & 0,39 & $* * *$ & $-0,04$ & $-0,11$ \\
\hline Futuro de milho - CC & 1,16 & 9,25 & $-0,02$ & 0,17 & & 0,05 & & 0,18 & & $-0,11$ & $-0,18$ \\
\hline Futuro de açúcar - CC & 0,98 & 10,51 & $-0,04$ & 0,49 & **** & $-0,23$ & $* *$ & 0,60 & $* * *$ & 0,05 & $-0,04$ \\
\hline Futuro de álcool - CC & 1,16 & 10,74 & $-0,02$ & 0,30 & *** & $-0,09$ & & 0,24 & ** & 0,11 & 0,03 \\
\hline Futuro de boi - DIN 1 & 0,24 & 3,56 & $-0,31$ & $-0,22$ & ${ }^{* *}$ & $-0,07$ & & 0,01 & & $-0,07$ & $-0,07$ \\
\hline Futuro de café - DIN 1 & $-0,25$ & 8,98 & $-0,18$ & $-0,04$ & & 0,11 & & $-0,04$ & & 0,13 & 0,04 \\
\hline Futuro de milho - DIN 1 & 2,26 & 9,16 & 0,10 & $-0,06$ & & 0,02 & & 0,12 & & $-0,10$ & $-0,07$ \\
\hline Futuro de açúcar - DIN 1 & 1,66 & 10,42 & 0,03 & $-0,15$ & & $-0,08$ & & 0,10 & & 0,07 & $-0,03$ \\
\hline Futuro de álcool - DIN 1 & 1,55 & 10,70 & 0,02 & $-0,13$ & & $-0,08$ & & 0,09 & & 0,01 & $-0,01$ \\
\hline
\end{tabular}

Fonte: Resultados da pesquisa.

Notas: *** Significativo a $1 \%$; $* *$ significativo a $5 \%$. $\mathrm{VL}=$ posição vendida longa; $\mathrm{VC}=$ posição vendida curta; $\mathrm{CL}=$ posição comprada longa; $\mathrm{CC}=$ posição comprada curta; DIN 1 = posição dinâmica com média móvel de 21 dias úteis; DIN 2 = posição dinâmica com média móvel de 126 dias úteis.

Quanto à análise das carteiras de máxima utilidade, entre 1994 e 2000, as composições foram baseadas em ações (Ibovespa) e títulos de renda fixa (Selic) - como ocorreu na análise do período completo. Já no intervalo de 2001 a 2007, verificou-se, em todos os graus de aversão ao risco, presença de futuros agropecuários - Tabela $4^{11}$. Enquanto os agentes com pouca aversão a risco tiveram carteiras formadas especialmente por futuros de milho e ações, os com alta aversão formaram boa parcela dos portfólios com títulos de renda fixa - para $b_{i}$ igual a 4 , por exemplo, os componentes do investimento foram os títulos de renda fixa $(58,21 \%)$,

\footnotetext{
${ }^{11}$ Cabe mencionar que a Tabela 4 somente apresenta as participações dos ativos que tiveram peso diferente de zero. Além disso, neste segundo período, exceto os derivativos de soja não foram incluídos na análise, em razão de não ter sido observada negociação destes papeis entre maio de 2001 a setembro de 2002.
} 
ações $(16,76 \%)$, futuros de milho $(14,38 \%)$, ouro $(7,87 \%)$ e futuros de açúcar $(2,76 \%)$. A queda no peso dos derivativos agropecuários com aumento de $b_{i}$ deveu-se ao elevado risco desses papeis, em relação, especialmente, aos títulos de renda fixa. Os resultados, portanto, foram opostos aos de Anson (1999), que apontou aumento na participação dos futuros no portfólio, à medida que se elevava $b_{i}$, dada a capacidade de tais papeis na diversificação do risco da carteira.

Vale também destacar que os futuros, presentes nessas carteiras de máxima utilidade, foram representados por posições dinâmicas, o que indica possível superioridade de tais estratégias diante das estáticas. Nesse sentido, a utilização de análise gráfica nesse tipo de investimento ganha importância.

Tabela 4 - Retorno médio, risco e composição das carteiras que maximizavam a utilidade do investidor, no período de 1994 a 2000 e de 2001 a 2007

\begin{tabular}{ccccccccc}
\hline \multirow{2}{*}{ Período } & & \multirow{2}{*}{$\begin{array}{c}\text { Retorno } \\
\text { Médio }\end{array}$} & Risco & \multicolumn{6}{c}{ Pesos na carteira (\%) } \\
\cline { 7 - 10 } & & \%a.m) & $(\%$ a.m) & Ouro & IBOVESPA & SELIC & $\begin{array}{c}\text { Milho } \\
(1)\end{array}$ & $\begin{array}{c}\text { Açúcar } \\
(1)\end{array}$ \\
\hline \multirow{2}{*}{$2001-2007$} & 0,0 & 2,26 & 9,16 & - & - & - & 100,00 & - \\
& 0,5 & 2,15 & 6,06 & - & 42,82 & - & 57,18 & - \\
& 1,0 & 2,10 & 5,53 & 2,03 & 46,29 & - & 47,69 & 4,00 \\
& 2,0 & 1,80 & 3,23 & 13,84 & 29,83 & 25,59 & 25,74 & 5,00 \\
& 4,0 & 1,60 & 1,83 & 7,87 & 16,78 & 58,21 & 14,38 & 2,76 \\
\hline
\end{tabular}

Fonte: Resultados da pesquisa.

(1) As participações em futuros de milho e açúcar foram obtidas a partir de estratégias dinâmicas (com utilização de médias móveis de 21 dias úteis).

Com a amostra dividida em três períodos, também se verificou melhora nos desempenhos individuais em relação à análise com amostra completa. Destacaram-se as estratégias estáticas de café, no primeiro período (19941998), dinâmicas de açúcar (média móvel 21 dias úteis), no segundo intervalo de tempo (1999-2003), e dinâmicas de soja e álcool (média móvel 21 dias úteis), no último período (2004-2007). 
Observou-se que, de 1994 a 1998, as carteiras de máxima utilidade foram compostas por $100 \%$ de títulos atrelados à SELIC. Já nos outros intervalos (1999-2003 e 2004-2007), posições dinâmicas em futuros agropecuários estiveram presentes nos portfólios.

No período de 1999 a 2003, as participações dos derivativos de açúcar foram bastante significativas, quando a aversão ao risco do investidor se mostrou baixa - igual a 0,0 e 0,5 para $b_{i}$, e os pesos foram de $100,00 \%$ e $32,30 \%$, respectivamente. Com máxima aversão ao risco $\left(b_{i}=4\right)$, além da existência deste derivativo $(7,28 \%)$, verificou-se presença de títulos de renda fixa $(63,80 \%)$, ações $(10,45 \%)$, ouro $(10,48 \%)$ e futuros de milho $(7,89 \%)$.

Já no período 2004-2007, a composição das carteiras de máxima utilidade contou com posições dinâmicas em futuros de milho, soja e álcool, para $b_{i}$ igual a 1,2 e 4 , ou seja, foram incluídos derivativos sobre commodities em carteiras de investidores com elevada aversão ao risco. A razão para tal presença advém do potencial de diversificação do portfólio que esses contratos futuros tiveram no período de análise, como observado em Anson (1999).

Tabela 5 - Retorno médio, risco e composição das carteiras que maximizavam a utilidade do investidor, no período de 1994 a 1998, de 1999 a 2003 e de 2004 a 2007

\begin{tabular}{|c|c|c|c|c|c|c|c|c|c|c|}
\hline \multirow[b]{2}{*}{ Período } & \multirow[b]{2}{*}{$b_{i}$} & \multirow{2}{*}{$\begin{array}{l}\text { Retorno } \\
\text { Médio } \\
\text { (\%a.m) }\end{array}$} & \multirow{2}{*}{$\begin{array}{l}\text { Risco } \\
\text { (\% a.m) }\end{array}$} & \multicolumn{7}{|c|}{ Pesos na carteira $(\%)$} \\
\hline & & & & Ouro & IBOVESPA & SELIC & Milho ${ }^{(1)}$ & Soja ${ }^{(1)}$ & Açúcar ${ }^{(1)}$ & Álcool ${ }^{(1)}$ \\
\hline \multirow{5}{*}{$\begin{array}{l}1999- \\
2003\end{array}$} & 0,0 & 2,85 & 13,74 & - & - & - & - & - & 100,00 & - \\
\hline & 0,5 & 2,65 & 6,80 & 36,39 & 31,31 & - & - & - & 32,30 & - \\
\hline & 1,0 & 2,60 & 6,22 & 34,32 & 32,97 & - & 5,52 & - & 27,19 & - \\
\hline & 2,0 & 2,35 & 4,49 & 24,54 & 26,41 & 14,76 & 17,82 & - & 16,47 & - \\
\hline & 4,0 & 1,90 & 1,93 & 10,48 & 10,55 & 63,80 & 7,89 & - & 7,28 & - \\
\hline \multirow{5}{*}{$\begin{array}{l}2004- \\
2007\end{array}$} & 0,0 & 2,39 & 5,93 & - & 100,00 & - & - & - & - & - \\
\hline & 0,5 & 2,39 & 5,93 & - & 100,00 & - & - & - & - & - \\
\hline & 1,0 & 2,30 & 4,66 & - & 74,89 & - & 13,41 & 1,18 & - & 10,52 \\
\hline & 2,0 & 2,20 & 3,91 & - & 56,30 & - & 18,15 & 15,98 & - & 9,56 \\
\hline & 4,0 & 2,00 & 3,11 & - & 43,22 & 18,88 & 15,36 & 14,89 & - & 7,65 \\
\hline
\end{tabular}

Fonte: Resultados da pesquisa.

(1) As participações em futuros de milho, soja, açúcar e álcool foram obtidas a partir de estratégias dinâmicas (com a utilização de médias móveis de 21 dias úteis). 


\section{Conclusões}

A inserção de papeis atrelados aos preços de commodities tem sido frequente nos mercados financeiros mundiais, especialmente nos Estados Unidos. Investidores institucionais e bancos, em geral, vêm utilizando derivativos sobre os mais diversos produtos (metais, combustíveis, grãos, alimentos e animais), com o objetivo de elevação do desempenho de seus portfólios.

Tal quadro tem sido intensificado a partir do início da década de 2000, com o consumo crescente de alimentos, aliado à busca incessante por combustíveis renováveis alternativos ao petróleo. Com a elevação dos preços de várias dessas commodities, os futuros sobre tais ativos têm conferido oportunidades de elevação nas taxas de retorno dos investimentos.

Esta pesquisa confirmou o fato anteriormente exposto, ao constatar a presença dos futuros agropecuários, negociados na BM\&FBOVESPA, nas carteiras de máxima utilidade esperada, quando considerados os períodos de 1999 a 2007. Verificou-se também que, em geral, esses papeis são considerados bastante arriscados pelos agentes, pois, com o aumento do coeficiente de aversão ao risco, houve queda na participação no portfólio de máxima utilidade esperada, o que resultou em aumento de peso para os títulos de renda fixa.

Mediante um cenário futuro de provável queda nas taxas de juro na economia brasileira, os investimentos nos derivativos agropecuários colocam-se como alternativas ainda mais interessantes para diversificação de riscos e alavancagem do retorno. Para isso, torna-se indispensável o conhecimento do mercado agropecuário no qual se deseja atuar, com o intuito de fundamentar as previsões sobre tendências futuras dos preços do produto, além do uso de análises técnicas que visem inferir os movimentos de curto prazo. 
Cabe ainda ressaltar que outras pesquisas podem avançar a análise aqui feita, ao incluir os custos das operações com derivativos, a possibilidade de alavancagem nesses mercados e a adoção de outras funções de utilidade menos restritivas.

\section{Referências}

AKEY, R.P. Commodities: a case for active management. Journal of Portfolio Management, New York, v. 8, n. 2, p. 8-29, 2005.

ANSON, M.J.P. Maximizing utility with commodity futures diversification. Journal of Portfolio Management, New York, v. 25, n. 4, p. 86-94, 1999.

BODIE, Z.; ROSANSKY, V. Risk and return in commodity futures. Financial Analysts Journal, Charlottesville, v. 36, n. 3, p. 27-39, 1980.

CENTER FOR INTERNATIONAL SECURITIES AND DERIVATIVES MARKETS. The benefits of managed futures. Disponível em:

$<\mathrm{http}$ ://cisdm.som.umas s.edu/research/pdffiles/ benefitsofmanagedfutures.pdf $>$. Acesso em: 20 ago. 2007.

COSTA, T.M.T.; PIACENTI, C.A. Utilização de contratos futuros agropecuários no perfil médio de investimentos dos fundos de pensão no Brasil. Revista Contabilidade \& Finanças, São Paulo, v. 19, n. 46, p. 59-72, 2008.

CREMERS, J.H, KRITZMAN, M.; PAGE, S. Portfolio formation with higher moments and plausible utility. Revere Street Working Paper Series, Financial Economics 272-12, 2003.

DAMODARAN, A. Gestão estratégica do risco - uma referência para a tomada de riscos empresariais. Bookman, 2009. 384 p. 
EDWARDS, F.R.; CAGLAYAN, M.O. Hedge fund and commodity fund investments in bull and bear markets. Journal of Portfolio Management, New York, v. 27, n. 4, p. 97-108, 2001.

EGELKRAUT, T.M.; WOODARD, J.D.; GARCIA, P.; PENNINGS, J.M.E. Portfolio diversification with commodity futures: properties of levered futures. In: NCR-134 Conference on applied commodity price analysis, forecasting and market risk management, 2005, St. Louis. 14 p. Disponível em: <http://www.farmdoc.uiuc.edu/nccc134/conf_2005/pdf/ confp05-05.pdf>. Acesso em: 10 jan. 2008.

ELTON, E.; GRUBER, M.; BROWN, S.J.; GOETZMANN, W.N. Moderna teoria de carteiras e análise de investimentos. São Paulo: Atlas, 2004. 602 p.

ERB, C.B.; HARVEY, C.R. The tactical and strategic value of commodity futures. Financial Analysts Journal, Charlottesville, v. 62, n. 2, p. 6997, 2006.

FABOZZI, F.J.; FOCARDI, S.M.; KOLM, P.N. Financial modeling of the equity market - from CAPM to cointegration. Hoboken: John Wiley \& Sons, 2006. 651 p.

FORTENBERY, T.R.; HAUSER, R.J. Investment potential of agricultural futures contracts. American Journal of Agricultural Economics, Milwaukee, v. 72, n. 3, p. 721-726, 1990.

GORTON, G.; ROUWENHORST, G. Facts and fantasies about commodity futures. Financial Analysts Journal, Charlottesville, v. 62, n. 2, p. 47-68, 2006.

GREER, R.J. Conservative commodities: a key inflation hedge. Journal of Portfolio Management, New York, v. 4, n. 4, p. 26-29, 1978.

IDZOREK, T.M. Strategic asset allocation and commodities. Ibbotson Associates, 2006. Disponível em: 
$<$ http://corporate.morningstar.com/ib/documents/ MethodologyDocuments/IBBAssociates/Commodities.pdf $>$. Acesso em: 20 dez. 2007.

JENSEN, G.R.; JOHNSON, R.R.; MERCER, J.M. Efficient use of commodity futures in diversified portfolios. The Journal of Futures Markets, New York, v. 20, n. 5, p. 489-506, 2000.

JENSEN, G.R.; JOHNSON, R.R.; MERCER, J.M. Tactical asset allocation and commodity futures. Journal of Portfolio Management, New York, v. 28, n. 4, p. 100-111, 2002.

KROLL, Y.; LEVY, H.; MARKOWITZ, H.M. Mean-variance versus direct utility maximization. Journal of Finance, Chicago, v. 39, n. 1, p. 47-61, 1984.

MARKOWITZ, H.M. Portfolio selection. Journal of Finance, Chicago v. 7, n. 1, p. 77-91, 1952.

MARKOWITZ, H.M. The optimization of a quadratic function subject to linear constraints. Naval Research Logistics Quarterly, New York, v. 3, n. 1, p. 111-133, 1956.

MARKOWITZ, H.M. Portfolio selection: efficient diversification of investments. New York: John Wiley \& Sons, 1959. 344 p.

MATTOS, F.L.; FERREIRA FILHO, J.B.S. Utilização de contratos futuros agropecuários em carteiras de investimento: uma análise de viabilidade. Revista de Economia e Sociologia Rural, Brasília, v. 41, n. 1, p. 9-30, 2003.

PULLEY, L.B. A general mean-variance approximation to expected utility for short holding periods. Journal of Financial and Quantitative Analysis, v. 16, p. 361-373, 1981. 
QUARANTA, M. Encontro das águas. Resenha BM\&F, São Paulo, n. 171, p. 19-23, 2007.

SZADO, E. A. VIX Futures and options: case study of portfolio diversification during the 2008 financial crisis. Working paper, University of Massachusetts at Amherst, 2009. Disponível em: <http://ssrn.com/ abstract $=1403449>$. Acesso: 10 ago. 2009.

SILVEIRA, R. L. F.; BARROS, G. S. C. Uma análise da alocação de contratos futuros sobre commodities em portfólios diversificados. Anais do XLVII Congresso da Sociedade Brasileira de Economia e Sociologia Rural, Porto Alegre, 2009.

YOU, L.; DAIGLER, R.T. Downside four-moment tail risk with financial and commodity futures diversification. In: Financial Management Association Conference, 2007, Orlando. Disponível em: <http:// w w w. f m a. o r g / O r l a n d o / P a p e r s / Commodity_Futures_Diversification.pdf>. Acesso em: 10 jan. 2008.

Abstract: This study investigates the composition of maximum expected utility portfolio, considering stocks, bonds, gold, dollar and agricultural futures contract, between August of 1994 and December of 2007. From the optimal combinations of risk-return (calculated by Markowitz algorithm) and the use of a quadratic utility function (with different levels of risk aversion), were obtained portfolios that maximizes expected utility. The commodity futures were not present in the maximum expected utility portfolios for the complete period, 1994-2000. However, with division of sample in two and three periods, the commodity futures were included in these portfolios during the 2000s. Furthermore, in general, with the risk aversion increase, the participation of these papers in the portfolio had fall.

Keywords: Portfolio, agricultural futures contract, utility. 
REVISTA DE ECONOMIA E AGRONEGÓCIO, VOL.7, $N^{\circ} 2$ 